Cutts, R. E.; Burns, Susan E.; Griffith, J. D.; Ehrman, B. R.

Comparison of the Rate of Evaporation from Six Rolled Erosion Control Products

Verfügbar unter / Available at:

https://hdl.handle.net/20.500.11970/100240

Vorgeschlagene Zitierweise / Suggested citation:

Cutts, R. E.; Burns, Susan E.; Griffith, J. D.; Ehrman, B. R. (2010): Comparison of the Rate of Evaporation from Six Rolled Erosion Control Products. In: Burns, Susan E.; Bhatia, Shobha K.; Avila, Catherine M. C.; Hunt, Beatrice E. (Hg.): Proceedings 5th International Conference on Scour and Erosion (ICSE-5), November 7-10, 2010, San Francisco, USA. Reston, Va.: American Society of Civil Engineers. S. 222-230. 


\title{
Comparison of the Rate of Evaporation from Six Rolled Erosion Control Products
}

\author{
R.E. Cutts $^{1}$, A.M. ASCE, S.E. Burns ${ }^{2}$, M. ASCE, P.E., J.D. Griffith ${ }^{3}$, P.G., P.E., and \\ B.R. Ehrman ${ }^{4}$, P.E.
}

${ }^{1}$ PSI, Inc., 2930 Eskridge Road, Fairfax VA 22031; PH 1 (703) 698-9300; email: ross.cuttşagmail.com

${ }^{2}$ School of Civil and Environmental Engineering, Georgia Institute of Technology, Atlanta, GA 30332-0355; PH 1 (404) 894-2285; email: sburns@gatech.edu

${ }^{3}$ Georgia Department of Transportation, 600 West Peachtree NW Atlanta, GA 30308; PH 1(404) 631-1547; email: jogriffithra dot.ga.gov

${ }^{4}$ Georgia Department of Transportation, 600 West Peachtree NW Atlanta, GA 30308; PH 1(404) 631-1669; email: behrmanfa dot.ga.gov

\begin{abstract}
Rolled Erosion Control Products (RECPs) are temporary degradable or longterm non-degradable materials designed to reduce soil erosion and assist in the growth, establishment, and protection of vegetation. Although the diversity of products within the RECP category is beneficial from a cost competitive standpoint, it is often difficult for a designer to distinguish between the function of the materials due to the sheer number of products available. Six RECPs were tested in this experimental study to quantify the level of evaporation protection conferred to the underlying soil by the presence of an RECP. Moist soil was placed in polyethylene test containers to ensure one-dimensional vertical flow of the soil moisture during evaporation. Each RECP was tested in two conditions: full sun and buried in topsoil in shade. Additionally, a control test was performed on the soil, with no RECP covering. The mass of the soil container was monitored as a function of time and temperature throughout the day. Soil temperature remained fairly constant throughout the test, at approximately $32^{\circ} \mathrm{C}\left(89^{\circ} \mathrm{F}\right)$, while air temperature ranged from $30-37^{\circ} \mathrm{C}$ $\left(86-99^{\circ} \mathrm{F}\right)$. In all cases, the presence of the TRM dramatically reduced the rate of evaporation, both when shaded and when exposed to full sun.
\end{abstract}

\section{INTRODUCTION}

RECPs play a significant role in engineering projects where erosion control is of importance. RECPs are designed to reduce erosion in channels and slopes and to encourage rapid revegetation to further reduce a soil's susceptibility to erosive forces. Available products are manufactured to exist in a diverse range of environmental conditions, so they have a large variation in their characteristic properties. RECPs designed for long-term, non-degradable applications are typically known as turf reinforcement mats (TRMs), and temporary degradable RECPs made for short-term applications are known as erosion control blankets (ECBs). Depending on their function, the products are manufactured with a variety of materials, ranging from ultraviolet-stable or photodegradable polyethylene to natural fibers that are readily biodegradable. 
In addition to shielding soil from the erosive forces of rain, RECPs also function to reduce the rate of evaporation from soils. Evaporation is a complex function of system properties including temperature, humidity, air velocity, and the characteristics of the porous media (Shokri et al., 2008). The parameter of interest is typically the rate of evaporation, which is characterized by two primary stages: a high water content stage where the rate of evaporation is relatively constant and similar to that of free, bulk water, and a low water content stage where the rate of evaporation is controlled by the rate at which water can move through the pore space; that is, the rate of diffusive mass transfer of water (Shokri et al., 2009). This study focused on evaporation from low water content soils, in which the water in the soil is held in a meniscus in the pendular state. When a soil is in the pendular state, water occurs as a coating at the contacts of soil particles, and the pore space of the soil is occupied primarily by air (Cho and Santamarina, 2001). In the case of two contacting soil spheres, the meniscus is typically approximated according to the toroidal approximation (Figure 1).

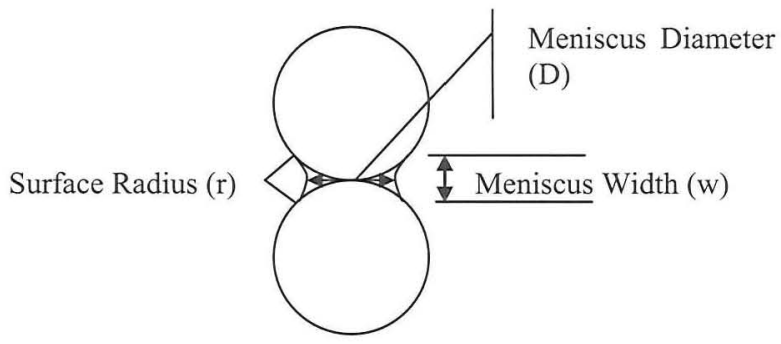

Figure 1. Evaporating water from the menicus between two contacting soil spheres.

Mathematically, the toroidal approximation can be described as follows:

$$
\begin{aligned}
& \vec{R}(u, v)=[(w \cdot r+\cos (u) \cdot r) \cdot \cos (v), \cdot(w \cdot r+\cos (u) \cdot r) \cdot \sin (v), r \cdot \sin (u)] \\
& \vec{R}_{u}=\left(\frac{d R}{d u}\right), \vec{R}_{v}=\left(\frac{d R}{d v}\right) \\
& T=\operatorname{cross}\left(\vec{R}_{u}, \vec{R}_{v}\right), \text { and Norm }=a b s\left(\sqrt{\left(T_{x}^{2}+T_{y}^{2}+T_{z}^{2}\right)}\right) \\
& S A=\int_{\pi-0.5 \theta}^{\pi+0.5 \theta} \int_{0}^{2 \pi} \text { Norm } \mid d u d v
\end{aligned}
$$




$$
\theta=\arccos \left(\frac{2 \cdot r^{2}-w^{2}}{2 \cdot r^{2}}\right)
$$

Where $w=$ width of meniscus, $r=$ surface radius, $\theta=$ angle of curvature, and $u$ and $v$ vary between 0 and $2 \pi$.

Subsequently, the fluid volume within the meniscus can be determined as the difference between the volume of liquid in the toroidal approximation and the volume of solid spheres within the meniscus:

$$
\begin{aligned}
& \text { Volume }_{\text {liquid }}=\pi \int_{-0.5 w}^{0.5 w}\left(r+\frac{D}{2}\right)^{2}-\left(\sqrt{r-x^{2}}\right)^{2} d x \\
& \text { Volume }_{\text {solids }}=2 \cdot\left[\left(\pi \cdot\left(\frac{w}{2}\right)^{2} \cdot r_{s}\right)-\left(\frac{\pi(w / 2)^{3}}{3}\right)\right]
\end{aligned}
$$

Where: $r_{s}=$ radius of contacting solid sphere, $D=$ liquid meniscus diameter. An indepth study of the rate of evaporation between two contacting silica spheres revealed the controlling parameters that govern the evaporation of water from two contacting silica spheres were the temperature, relative humidity, and the shape of the meniscus (Cutts and Burns, 2009). Soil particle shape will also influence the rate significantly.

In contrast, the rate of evaporation of water from a free surface is not governed by the change in the shape of the meniscus at soil particles, and can be determined relatively simply according to the following equation (Adamson and Gast, 1997):

$$
Z=\left(P-P_{v}\right)\left(\frac{1}{2 \pi M R T}\right)^{0.5}
$$

Where $Z$ = condensation rate (assumed to be equal to the evaporation rate at equilibrium), $P=$ saturated vapor pressure, $P_{v}=$ ambient partial pressure, $M=$ molecular weight, $R=$ gas constant, and $T=$ temperature. Evaporation of water from a free surface at a temperature of $35^{\circ} \mathrm{C}$ and relative humidity of $56 \%$, yields a rate of $1.60 \times 10^{-3} \frac{\mathrm{g}}{\mathrm{mm}^{2} \mathrm{sec}}$.

\section{MATERIALS AND METHODS}

Six RECPs, all supplied by North American Green (Poseyville, Indiana, USA), were chosen for study: $\mathrm{Vmax}^{3} \mathrm{P} 550, \mathrm{Vmax}^{3}, \mathrm{SC} 150, \mathrm{C} 125 \mathrm{BN}, \mathrm{S} 75$, and DS150. These six were chosen because they represented a wide range of longevity of projected performance. The tested products were intended for applications that ranged from permanent to short term (60 days), and ranged from construction with relatively stable polymers to bio- or photodegradable polymers and natural fibers 
(Table 1 and Figure 2). The products intended for permanent application (Vmax ${ }^{3}$ P550 and $V \max ^{3}$ ) were constructed with polypropylene nets designed for stability in the presence of ultraviolet light, while products intended for shorter term applications of two years or less (SC150, DS150, S75) were designed with one or more photodegradable nets. One tested product, $\mathrm{C} 125 \mathrm{BN}$, was designed with both a biodegradable net and matrix.

Table 1. Characteristics of RECPs Tested

\begin{tabular}{|l|c|l|l|}
\hline Manufacturer & Product & Material & Application \\
\hline North American Green & Vmax $^{3}$ P550 & $\begin{array}{l}\text { Polypropylene nets } \\
\text { and matrix }\end{array}$ & Permanent \\
\hline North American Green & Vmax & $\begin{array}{l}\text { Polypropylene } \\
\text { nets, coconut fiber } \\
\text { matrix }\end{array}$ & Permanent \\
\hline North American Green & SC150 & $\begin{array}{l}\text { Polypropylene } \\
\text { nets, straw/coconut } \\
\text { fiber matrix }\end{array}$ & 24 months \\
\hline North American Green & C125BN & $\begin{array}{l}\text { Jute net, coconut } \\
\text { fiber matrix }\end{array}$ & 24 months \\
\hline North American Green & S75 & $\begin{array}{l}\text { Polypropylene net, } \\
\text { straw matrix }\end{array}$ & 12 months \\
\hline North American Green & DS150 & $\begin{array}{l}\text { Polypropylene } \\
\text { nets, straw matrix }\end{array}$ & 60 days \\
\hline
\end{tabular}

A medium plasticity silt $(\mathrm{MH})$ with a liquid limit $(\mathrm{LL})=63.9 \%$ and plasticity index $(\mathrm{PI})=17.1 \%$ was used in the evaporation experiments. The soil is known locally as Piedmont saprolitic soil (Fulton County, Georgia, USA), and has a reddish hue due to the presence of extensive iron oxide coatings on the soil grains; the grain size distribution shows approximately $70 \%$ fines content (Figure 3). After thoroughly mixing the soil with City of Atlanta tap water to ensure uniform distribution of moisture, the soil was compacted into waterproof containers at a moisture content of $10.4 \%$. The containers had dimensions of $13.3 \mathrm{~cm}$ by $9.5 \mathrm{~cm}$ by $6.4 \mathrm{~cm}$ and were impermeable on all sides except the top to force a one-dimensional vertical evaporative flux. The mass of the containers was measured as a function of time, and the measured mass difference was attributed to evaporative losses from the test soil. Both air and soil temperatures were measured throughout the duration of the test as well. 

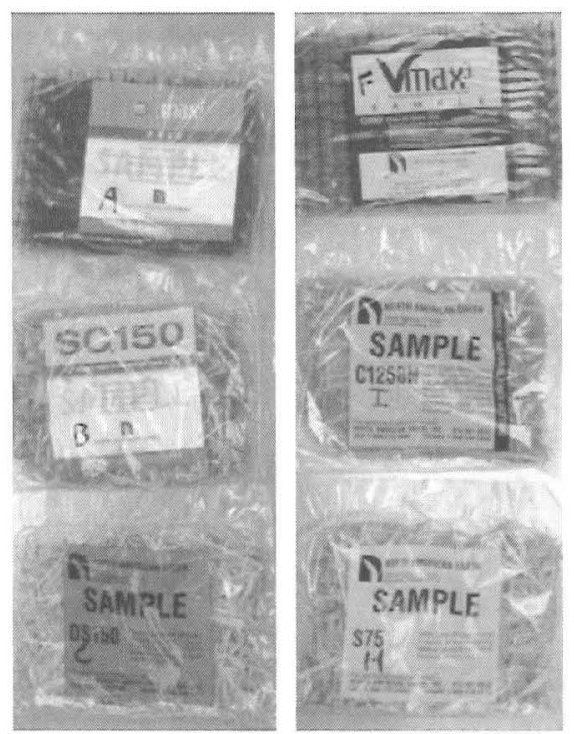

Figure 2. Rolled erosion control products tested in the evaporation study.

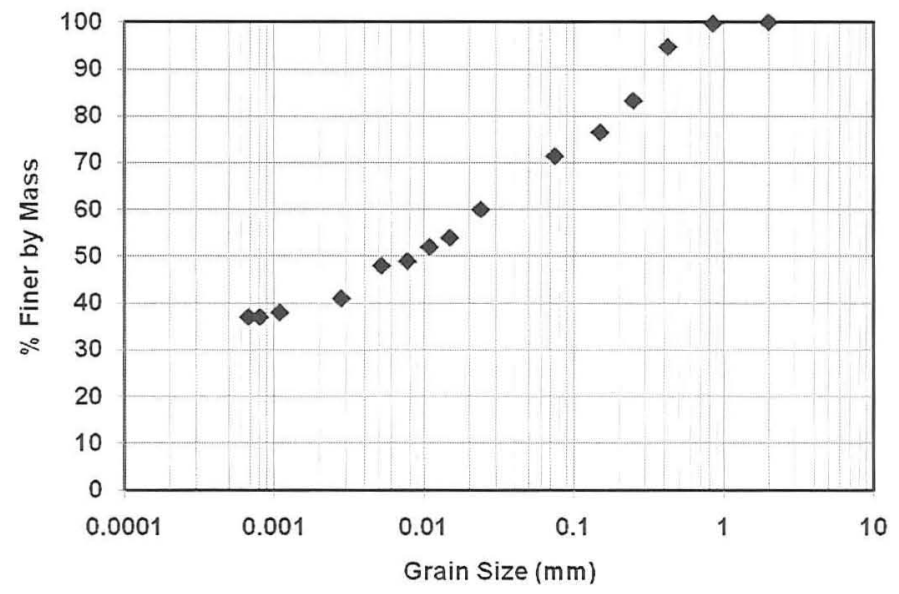

Figure 3. Grain size distribution for the Piedmont soil used in the experiments. 


\section{RESULTS}

The recorded air and soil temperatures demonstrated that the soil temperature remained relatively stable throughout the duration of the testing program in spite of the significant increase recorded in the prevailing air temperature (Figure 4).

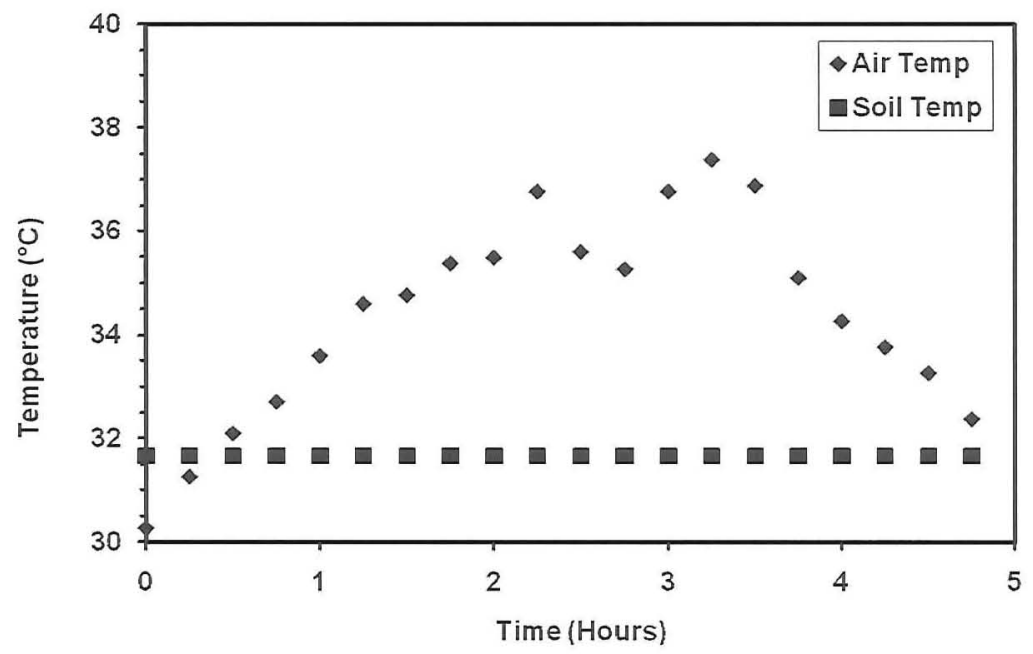

Figure 4. Soil and air temperature throughout the test duration.

For the RECPs that were tested in full shade, the rate of evaporation observed for the samples with RECP covering was less than half the rate that was observed in the control case with no covering (Figure 5). Similar results were seen in the case where the soil containers were placed in full sun (Figure 6). 


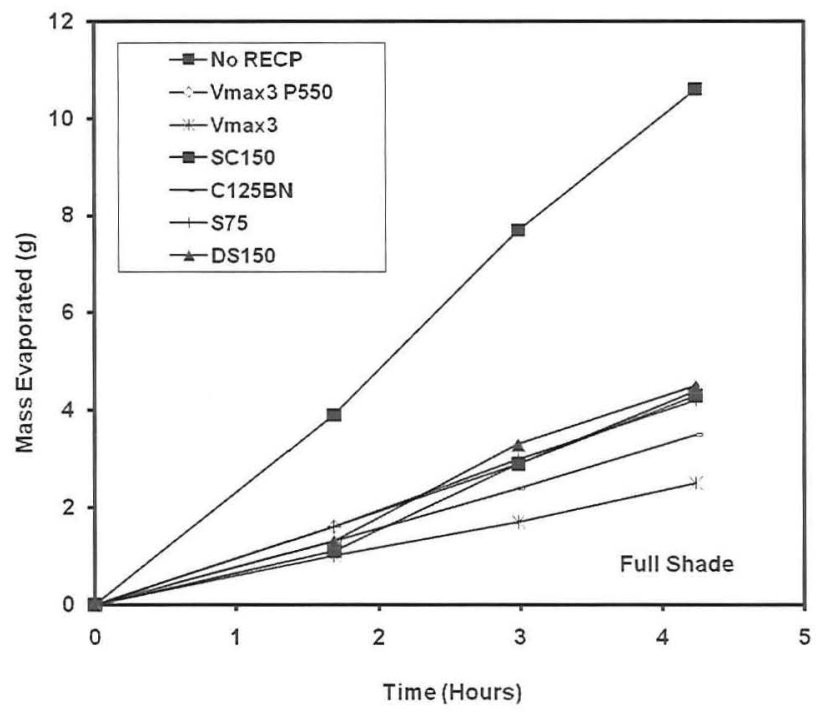

Figure 5. Rate of mass evaporation in full shade throughout the test duration.

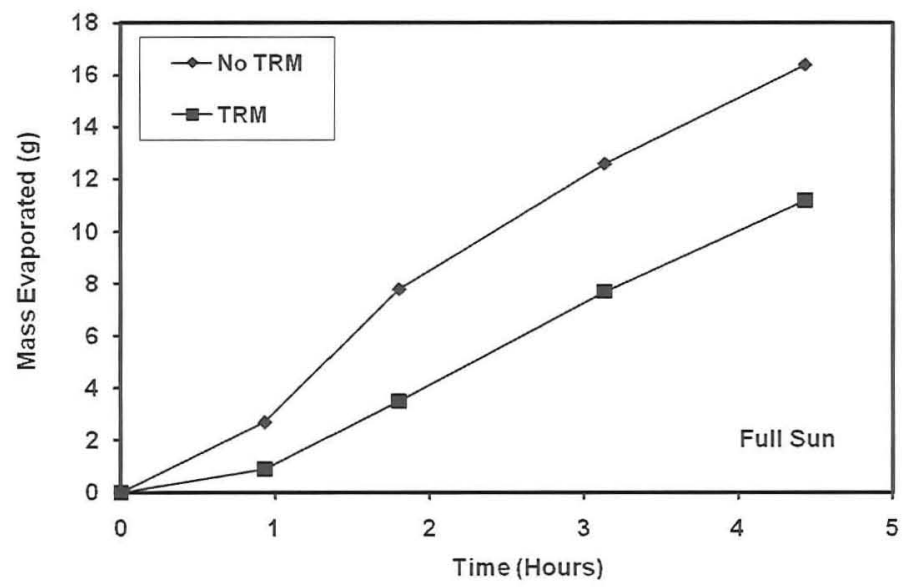

Figure 6. Comparison of the rate of evaporation in full sun, with and without TRM covering. 
Examination of the data normalized in terms of flux demonstrated that the differences between the flux from the six different RECPs were relatively small, with $\mathrm{Vmax}^{3}$ demonstrating the lowest flux at apprximately $25 \%$ of the flux from the uncovered control case (Figure 7). In general, the evaporative flux was $60-70 \%$ lower than the flux recorded in the case where the soil was left uncovered. Interestingly, little correlation was observed between the RECP matrix material and the evaporative flux. The two RECP samples that used straw as the matrix (S75 and DS150) demosntrated similarly high values of flux as were observed in the polypropylene sample (Vmax ${ }^{3}$ P550) and the straw/coconut sample (SC150). The lowest observed evaporative flux was from the $\operatorname{Vmax}^{3} \mathrm{RECP}$, which occurred in the case of the coconut fiber matrix. Despite the significantly different materials and structure within the RECP matrices, the relative differences in evaporative flux were small, and effectively minor when compared on a product to product basis.

Comparing the rate of evaporation from the soil samples to that previously calculated for evaporation from the free surface of water demonstrated that evaporative losses were much lower in soil systems. As was anticipated, the presence of the soil particles led to formation of menisci, which created tensile forces in the water at the particle surface and greatly decreased the rate of mass transfer away from the particles. Mass transfer was also limited within the tortuous pore space of the soil, further reducing the rate of water movement. The rate of evaporation from a free water surface under the conditions described above is approximately five orders of magnitude greater than that observed in the tested soils, with or without RECP covering.

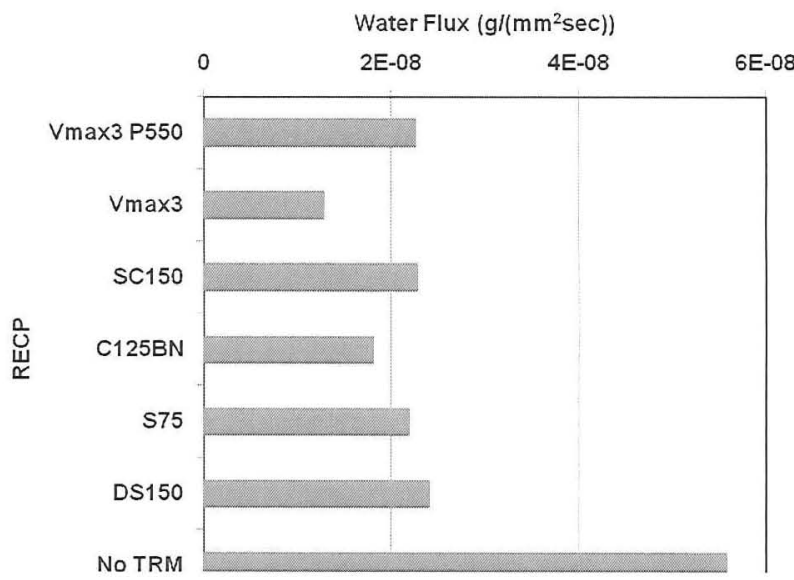

Figure 7. Comparison of water flux from 6 RECPs in shaded conditions. 


\section{CONCLUSIONS}

Ultimately, the reduction in evaporative flux due to the presence of the RECP had two effects: (1) it allowed the soil to retain additional moisture, thereby increasing the amount of water that will be bio-available; and (2) it increased the amount of time the soil remained in the unsaturated state, which increases the tensile forces between the soil particles and reduces the soil's erodibility. The presence of the RECP is believed to have resulted in a reduced local temperature at the soil and air interface and limited the mass transfer of water from the soil surface, both of which resulted in the reduction of the net evaporative flux from the soil that was covered with an RECP.

\section{ACKNOWLEDGEMENTS}

The authors thank North American Green for the donation of the samples that were used in this investigation. Partial funding for this investigation was provided by the Georgia Department of Transportation, and the authors are grateful for the financial support.

\section{REFERENCES}

Adamson A.W., Gast A.P. (1997) Physical Chemistry of Surfaces. 6th ed. John Wiley \& Sons, Inc.

Cho G.C., Santamarina J.C. (2001) Unsaturated particulate materials-particle-level studies. Journal of Geotechnical and Geoenvironmental Engineering 127:8496.

Cutts R.E., Burns S.E. (2009) Evolution of Surface Area-to-Volume Ratio for a Water Meniscus Evaporating Between Contacting Silica Spheres. Journal of Colloid and Interface Science 343:58-64.

Shokri N., Lehmann P., Or D. (2009) Characteristics of evaporation from partially wettable porous media. Water Resources Research 45.

Shokri N., Lehmann P., Vontobel P., Or D. (2008) Drying front and water content dynamics during evaporation from sand delineated by neutron radiography. Water Resources Research 44. 